
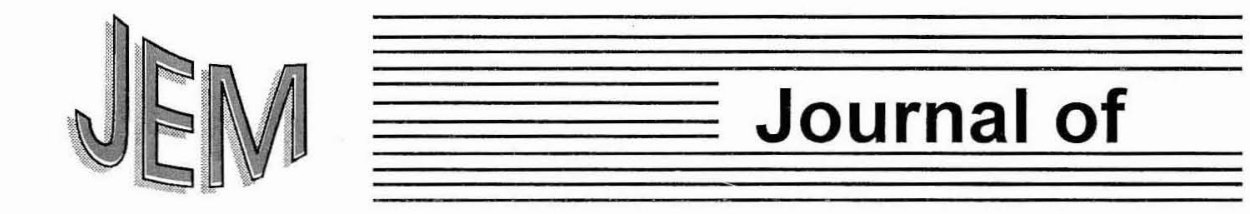

\title{
Educational Management
}

A Bi-annual Publication of

THE INSTITUTE FOR EDUCATIONAL PLANNING AND

ADMINISTRATION

(IEPA)

University of Cape Coast, Ghana 
Journal of Educational

Management Vol. 2, 148 - 154

November 1999

\section{POLYTECHNIC EDUCATION IN GHANA : CAREER OPPORTUNITIES}

\section{A. Amuzu-Kpeglo}

This paper begins with the optimism that the importance of the Polytechnic institution in tertiary education and its role in national development is now seriously unfolding. At the very inception of the Polytechnic and the Workers College in the First Republic, the founding fathers meant very well for the two types of educational institutions. But the best the Polytechnic could achieve in that era was to operate essentially in training students in specific trades and vocations to the City \& Guilds Certificate level.

The assumption was that graduates of the Polytechnic would have little or no management responsibility in the world of work. Their technical and professional training was focused mainly on acquisition of shop experience for salaried employment. "Polytechnics before 1993 produced, in the majority, personnel that industry and commerce would classify as operatives at the lower end of the work force spectrum" (Daily Graphic July 2, 1997 p. . 9). Fortunately, today the Polytechnic is required, and hopefully, being equipped to train highly skilled technicians and middle level management personnel who, given all the opportunities and incentives, will rise to top executive management positions without betraying or forsaking their roots.

The opportunities and incentives we have in mind could best be described as "Career Opportunities" available to the graduate/diplomate of the Higher National Diploma Programme. These are very explicitly detailed out in the Ho Polytechnic Career Prospectus (1997 - 1998) document. The review below follows very closely the career descriptions as outlined by the Ho Polytechnic. In other words, this paper is limited to the career opportunities of the HND Programme as at now available at the Ho Polytechnic. We are yet to examine other career programmes as they exist in sister polytechnic institutions.

The Ho Polytechnic started as Ho Technical Institute in 1968 with the 
primary objective of providing pretechnical education to middle school leavers. The Institute became a Polytechnic in 1986 but essentially remained a second cycle institution within the Ghana Education Service. In 1993 Ho Polytechnic was upgraded alongside five of its counterparts in the country into a tertiary institution with the promulgation of the PNDC Law 321. The Polytechnics are now required to provide tertiary education through full-time courses in the fields of manufacturing, commerce, science and technology. They are encouraged to offer courses in technical subjects at the tertiary level, and to provide opportunity for development, research, and publication of research information.

The Polytechnics, with the assistance from collaborating institutions, have designed relevant curricula and training programmes leading to the award of the Higher National Diploma (HND). These programmes are of three years duration and are expected to complete the tertiary cycle of technical education and provide capacity for training of a new breed of graduates who can confidently combine theory with practice and conduct practical field and action research.

The HND Programme in the Polytechnic has a conspicuous advantage over the First Degree in the University. The Principal of Ho
Polytechnic states categorically that although the Polytechnic in Ghana today is a tertiary institution similar to the University, "the underpinning philosophy of Polytechnic education and training is different. At the Polytechnic, the curriculum is career focused with emphasis on the acquisition of hands-on practical and entrepreneurial skills". These hands-on practical and entrepreneurial skills as provided by the various schools and departments afford the HND graduate career opportunities which are unique and challenging.

\section{Agricultural Engineering}

Agriculture is the economic sector employing the largest percentage of the population of Ghana. Agricultural Engineering is the discipline that provides the mechanical tools for Agriculture.

The HND Programme in Agricultural Engineering offers students sound understanding of the skills, processes and techniques involved in the design, manufacture, operation and maintenance of agricultural machinery. The programme also trains students in agricultural production (crop and animal husbandry), soil and water engineering (including irrigation, drainage, soil conservation) as well as crop storage and processing systems.

The career prospects in this field 
are wide and challenging. The graduate will help in the modernisation of production systems through intensive application of agricultural engineering techniques. $\mathrm{He}$ will fulfil a wide variety of functions in Forestry (logging), Mining and Agricultural Mechanization.

The Higher National Diploma in Agricultural Engineering puts you on the career path to become a Production Engineer, Hydrologist, Soil and Water Engineer, etc. Specialisation in Post Harvest Technology also qualifies you to work in Food Processing Industries. You may also branch into Water Supply and Sanitation Engineering, Dam Building in Irrigation, Land Reclamation and large-scale civil works.

\section{Electrical/Electronic Engineering}

At a time when electrical technology is developing rapidly in the third world, career prospects in electrical engineering are good and increasingly challenging.

Man's processes in modern industry are electrically powered and the working of a electrical engineer is related to the generation and distribution of electricity for power, heat and light. The technician or engineer in this field is concerned predominantly with designing, developing, installing, fault finding and remedial repairs. Testing of electrical motors, generators, alternators, transformers, transmission lines, cables and switching gear also forms essential segments of electronic engineering. The technician is an integral part of the engineering team and as such is expected to liaise with both the engineer and the artisan.

The HND graduate may be employed in industries and specialist fields such as Radio Communications, Rural Electrification, Digital Systems, Medical Instrumentation and Process Instrumentation Control. The working environment therefore ranges from management and maintenance domains to research and development.

\section{Mechanical/Automotive Engineering}

Mechanical Engineering is the most general of all the industry-based occupations as it ranges across every stage of the manufacturing process. The HND graduate in Mechanical Engineering is to be found in all manner of industries: those making steel and bricks, mining and power generating stations, oil refineries and foundries, textile factories, etc. He/ she can find employment as designer in development work, quality control, assembly plants and in management. The Automotive Engineering graduates could pursue such careers 
as Service Managers, Field Service Engineers, Automotive Equipment Parts Manager, Transport Officer/ Manager and as a Technology Teacher.

\section{School of Business \& Management Studies}

\section{Accountancy}

The wide knowledge of accounting functions of the HND graduate makes his/her task an important one for decision making and the smooth running of any business concern. The prospects are bright as the graduate may be expected to supervise and direct the recording of general accounting information, analyse and produce the information required for the effective running of a business.

His/her day-to-day duties will depend on the needs of the organisation which will manifest in internal auditing, write-up of books and records, costing systems, wages and salary control systems, statements, budget, etc. The HND graduate can therefore be employed at government departments, educational institutions, private industries, commercial and banking sectors, and private accounting firms.

\section{Marketing}

Marketing personnel are responsible for planning the marketing programme implementing the programme and evaluating the performance of the programme. In order to do this efficiently, marketers need to develop expertise in many areas including marketing research, sales analysis and forecasting, advertising, sales promotion, public relations, distribution and the generation of profit. The wide range of responsibilities, with the imperative requirement to travel makes it a demanding yet rewarding career choice.

The HND graduate may be employed as a Marketing Officer in business establishments, central and local government administration, service and manufacturing industries. He/she may also establish his/her own marketing ventures.

\section{Secretary And Management Studies}

This exiting and challenging diploma programme allows a Secretary to show his/her creative and innovative abilities, utilizing fully all the advanced functions of computer software programmes. He/she will be very versatile as she will compose her own correspondence, and re-write dictated matter. His/her ability to work without assistance relieves pressure from the chief executive.

Graduates of this diploma programme are employed in the legal, 
personnel, building, financial, insurance and general business sectors. Higher technical computer skills with excellent public relations and communication skills could eventually lead the graduate to become a supervisor or the organiser of the "in-house" human resource development management.

\section{Statistics}

The need for statisticians is crucial in both developing and developed countries. Statistics deals with the collection, processing, analysis and interpretation of empirical data for decision making.

The HND programme is geared towards :

(i) training professional statisticians in the requisite skills, techniques and aptitudes needed to carry out various statistical programmes and activities, and

(ii) exposing students to related ancillary activities and skills that are needed to equip them adequately so as to satisfy the data generation requirements for solving challenging developmental problems.

The course also emphasises the acquisition of practical and problem solving skills to enable students to relate theory to practice so that they can play meaningful roles in solving current development problems at the various community levels through designing, implementing, monitoring, evaluating and sustaining development projects and programmes.

The career opportunities in Statistics are wide and diversified in direct response to, and in accordance with the trends of development and job prospects particularly at the community level. Employment opportunities and challenges exist for statisticians with training and expertise in all sectors of the economy and national life such as health. commerce, economic development, social stratification, agriculture, business education, engineering and technology.

\section{Building Construction}

The construction industry is a global one and will offer a person the opportunity to work anywhere in the world. Construction activities in Ghana will continue to expand particularly in the real estate industry, providing house and infrastructure for our growing population.

The Building Construction Programme provides general education in building technology. Once a person is qualified, he/she will co-ordinate all.the production activities on site. $\mathrm{He}$ is therefore 
trained to serve as a link between management and site personnel. The course also provides general education in quantity surveying which will enable one to determine quantities and cost of materials and labour required to fulfil a contract according to the plan and specification supplied. As a consultant a person can also offer professional advice and service to clients in a construction company.

The HND graduate can work in the public sector, industry and academic fields where teaching and research opportunities exist. He/she may also work with private building contractors and authorities, District Assemblies and community based organizations.

\section{Hotel, Catering And Institutional Management}

Ghana suffers from a great shortage of qualified local chefs, so the hospitality industry (hotels and restaurants) offers career opportunities. A person will be able to develop wonderful recipes and style food (e.g. cakes) as well as ensure quality control. Research development and management opportunities also exist in food processing industries.

If you are smart and dedicated you will not have much difficulty finding a job once you are qualified. This diploma programme will qualify you to take charge of a large industrial unit/restaurant that serves meals to thousands of employees and customers daily or run your own outside catering business, restaurant, canteen or set up recreational centres. There is the opportunity of branching into teaching at the Senior Secondary School and in the tertiary level. You may also be employed in the hospitals as a Diet Supervisor or Catering Manager, and in hotels as Senior Housekeeper or Supervisor.

\section{School of Art and Design}

HND Fashion Design

And Modelling

A fashion/textile designer is responsible for the creation and development of the decign or pattern which is woven, knitted, usually on cloth. Fabrics, Furnishes, and Fashion are turned to life by the Fashion Designer. Ghana expects a booming tourist industry in the decades ahead. There is an assuring lucrative and challenging trade for well trained experts in fashion design and modelling.

The graduate can expect to enter the textile/clothing manufacturing industry or operate private enterprise. Opportunities also exist in the Performing Arts, Film and Television Companies. Talented designers can advance rapidly as avenues exist for 
one to enjoy recognition at a fairly early stage. For example, large establishments send competent designers out to shop overseas to select fabrics and trimmings and study fashion trends in the major cities of the world.

Job opportunities exist for graduates in Clothing Production, Productivity, Personnel, Work Study and Training, Quality Control, Administration, Merchandising and other related areas. They can also become Textile
Producers, Fashion Designers or Garment Producers. Opportunities also exist for them to teach in Junior and Senior Secondary Schools alongside private business.

In conclusion, it is not idle talk reassuring the holder of the HND qualification of a secured professional future in either commerce, industry, manufacturing, production, management, research or private enterprise

\section{References}

Afeti, G. M. "Polytechnic Education Ho Polytechnic. Career prospect in Ghana Today. Daily Graphic, (1997 - 1998).

July 2, 1997, p.9 